\title{
Numerical simulation of thermal and hydraulic performance of a micro plate-pin fin heat sink
}

\author{
Sakine Mehrabi, Saeid Kheradmand*, Omid R. Farivar \\ Department of Mechanical and Aerospace Engineering, Malek-Ashtar University of Technology, Shahin-Shahr, Isfahan \\ $83145 / 115$, Iran
}

Corresponding Author Email: kheradmand@mut-es.ac.ir

https://doi.org/10.18280/ijht.360315

Received: 10 Ocober 2017

Accepted: 30 August 2018

\section{Keywords:}

heat sink, hydraulic performance, thermal performance, numerical simulation

\begin{abstract}
In this paper, thermal and hydraulic performance of a plate-pin fin heat sink with air as cooling agent is investigated. The heat sink is subjected to a heat flux at a strip of its base. The numerical approach was validated using available experimental data. Hydraulic parameters including pressure drop and coefficient of friction and thermal parameters including Nusselt number and thermal resistance were considered for performance evaluations. In order to improve thermal performance of the heat sink, a single pin was inserted into each channel. The influence of the pin geometry, its dimensions, and location were studied. Various pin cross sections, including circular, elliptic and airfoil were studied. To investigate the effect of the circular pin location, seven different positions were considered for two sizes of the pin and the optimum location was derived. The simulation was carried out for five different Reynolds numbers in the range of 2730 to 6300 . It was found that pin insertion in the center of the heated region is an effective way to improve the thermal performance; also, using a larger pin results in a lower thermal resistance and a greater pressure drop. To evaluate overall performance, the heat sink effectiveness factor which represents a combination of the hydraulic and thermal performance was defined and corresponding figures were provided to derive an optimum geometry.
\end{abstract}

\section{INTRODUCTION}

Mini and micro heat sinks are employed for heat containment and cooling purposes in a wide variety of industries such as semiconductors, diode lasers, highperformance microprocessors, radars, mirrors for high power lasers and various heat exchangers. In fact, heat sink improves heat transfer rate by increasing the heat exchanging area as well as the amount of turbulence in fluid. Applying channels has a significant effect on convection mechanism in heat sink. These channels have a higher surface to volume ratio, thus enhancing the thermal performance. Besides, diminishing the hydraulic diameter of the channel leads to a higher rate of heat dissipation. Also, adding fins or minuscule cavities on the surface of the channel produces slight perturbations in the fluid, providing a higher heat transfer rate. The fins are applicable in a variety of shapes, sizes, materials, and layouts on the surface of the channel. Due to the extensive application of this equipment, various aspects such as thermal and hydraulic performance, optimizing size and shape, opting appropriate material, minimizing fabrication and operation costs need to be rigorously investigated.

Studying fluids in micro scale is relatively a novel concept, proposed in 1958 first in the Soviet Union and subsequently developed in the United States and Europe. Earlier applications were basically intended for military purposes which required predicting the fluid behavior in interior channels and vehicles on a millimeter scale and less. Considering the rapidly growing application of microelectromechanical equipment, the fluid behavior in small dimensions such as micro and mini channels is to be a great matter of concern [1]. Given the higher fluid rarefaction in micro scales, compared to that in macro scales, the continuity assumption is valid under certain circumstances, thus demanding for novel methods to be able to simulate such rarefied flows. The most crucial matter is the effect of the rarefaction of fluid, which has to be taken into account especially when the characteristic length is less than $1 \mu \mathrm{m}$ and the fluid is under particular pressure and temperature conditions. Qu et al. [2] in 2002 investigated the pressure drop and the heat transfer in a micro channel through experimental and numerical studies and indicated that Navier-Stokes and energy equations reasonably explain the fluid flow and the heat transfer in a micro channel heat sink. Minimizing entropy generation previously has been applied as a feasible method in order to investigate the performance of heat sink. In 2001, Culham et al. [3] studied the role of the shape of pin fin in heat sink performance. These researchers minimized the generated entropy, due to heat transfer and frictional losses, and derived an optimum design. By investigating these parameters, a heat sink with a minimum amount of entropy generation, thus the lowest possible operating temperature has been achieved. BarCohen and Iyengar [4] in 2003 adopted the same method in order to attain an optimum design for a heat sink with forced and free convective heat transfer which provides a desirable thermal performance, yet consuming the least amount of material and pumping power. Khan et al. [5] in 2006 also carried out a study using the same method to investigate the effect of geometry on heat transfer rate and pressure drop, simultaneously. In this study, the formulation of the dimensionless entropy generation rate has been derived using dimensionless parameters including dimensions of the pin, 
Reynolds number, Nusselt number and drag coefficient. Four different geometries including rectangular, square, circular and elliptical with the same peripheral area have been examined in terms of heat transfer, drag force, and entropy generation rate.

Heat sinks with pin fins in different shapes and dimensions have been examined considerably over recent years. In 2010 John et al. [6] investigated cylindrical and square geometries for the pin fins and explored several parameters such as the hydraulic diameter of the pin, aspect ratio (width to depth ratio of the pin), axial pitch distance and transverse pitch distance. In this study, the figure of merit which includes thermal resistance and pressure drop has been proposed to examine the performance of the heat sink. The results indicated that the cylindrical pin fin heat sink provides a higher performance at low Reynolds numbers (lower than 300) compared to that of the square ones, however, this behavior is inversed at high Reynolds numbers (higher than 300). Accordingly, opting for the appropriate geometry of the pin fin greatly depends on the Reynolds number. In addition, increasing the aspect ratio enhances the pin fin performance for both types of the pin fins studied. In 2011 Liu et al. [7] conducted an experimental study on a heat sink with micro square pin fins. For this purpose, two different pins with various widths were examined. The results revealed an improvement in mean Nusselt number and pressure drop according to novel expressions for the Nusselt number and the friction coefficient presented in their work. Yuan et al. [8] in 2012 explored a micro pin fin channel for the Reynolds numbers in the range of 3500 to 8000 . The studied heat sink was made of aluminum and the cooling fluid was air. At first, four types of pins, different in diameter, have been examined. Afterward, various configurations including staggered and in-line were explored. In this study, like the others [9], the coefficient of overall performance (the ratio of heat dissipation rate to required pumping work) was used to compare the performance of the different cases. The results indicated the diameter of pin fin as a crucial parameter, increasing of which leads to a significant mitigation in thermal resistance as well as the coefficient of overall performance. On the contrary, having the pins arranged staggered or in-line and the axial distance between them had a minor effect on the performance of the heat sink.

There have been several papers issued on optimizing the plate-pin fin heat sinks, in which researchers have attempted to propose general resolutions to optimize various types of heat sinks. In 1992 Knight et al. [10] based their calculations on attaining the lowest thermal resistance between the hottest location on the heat sink and the incoming fluid in order to accomplish the optimum geometry of a micro channel. In this method, the governing equations of convective and conductive heat transfer as well as the flow regime were considered and solved step by step for both laminar and turbulent regimes. This approach has been implemented by a number of researchers including Goldberg [11] for a copper heat sink with air as the fluid medium, Tuckerman and Pease [12] for a silicon heat sink with water as the cooling agent in laminar flow regimes and Philips for a silicon heat sink with water as the coolant agent in turbulent regimes. Furthermore, in 2011, Koz and Kosar [13] explored pin fin heat sink optimization for the Reynolds numbers between 1 to 100 and the heat fluxes between 20 to $500 \mathrm{~W} / \mathrm{cm}^{2}$. Case studies included the ratio of axial and transverse pitch to diameter and the ratio of height to diameter of pin. In this study, the Reynolds numbers between 1 to 100 and the heat fluxes between 20 to $500 \mathrm{~W} / \mathrm{cm}^{2}$ were taken into consideration and the continuity, Novier-Stokes and the energy equations were solved using numerical methods. This assessment suggested that the hydraulic and thermal performance of pin fin heat sink is impressively influenced by the ratio of height to diameter of pin fin. Due to emerging potentials of nano technology, the application of nano fluids has also been investigated by researchers. Sivakumar et al. [14], in 2015, experimented two different nano fluids, $\mathrm{Al}_{2} \mathrm{O}_{3}$ /water and $\mathrm{CuO}$ /ethylene glycol, and found that nano fluids, particularly $\mathrm{CuO} / \mathrm{EG}$, improve heat transfer coefficient in a serpentine shaped micro channel heat sink.

In some applications such as high power diodes, the heat flux exerted under the heat sink is non-uniform, resulting in a non-uniform temperature distribution and a hot spot, also, decreasing the performance of the heat sink. So that, it is necessary to design the heat sink according to the heat flux distribution. For this purpose, Hegde and Seetharamu [15] in 2008 explored the effects of various types of heat fluxes including upstream half heating, downstream half heating, center half heating and uniform heating throughout the base. Wang et al. [16] in 2009 investigated three types of channel heat sinks with different hydraulic diameters. The results implied that decreasing the micro channel width causes the maximum temperature of the heat sink to decline and increases the pressure drop. On the other hand, using channels with identical width for a non-uniform heat source is not a reasonable resolution due to emerging a hot spot and greater pressure drop. Hence, employing heat sinks with different channel widths, having the same amount of pressure drop, reduces the temperature rise significantly, thus being a proper option for dissipating non-uniform heat fluxes. In 2014 Huang and Chen [17] studied a heat sink subjected to jet impingement and a centered heat flux. Design parameters included pin width and height. For the purpose of optimization, the design parameters were continuously updated and heat resistance computations were iterated until an optimal point was reached. Adewumi et al. [18], in 2015, numerically investigated constructal design of a micro channel heat sink by changing the channel length (with constant volume). In this study, the physical properties of the cooling fluid were considered as a function of temperature. Using Bejan number, these researchers derived an optimal length for the channel. Also, in 2016, Liang et al. [19] numerically attempted to find an optimal design of plate pin fin heat sink with natural convection using entropy generation minimization method. They studied geometric parameters such as fin height, number and thickness. Using particle swarm algorithm, they found that the thickness of fin is the most effective parameter on entropy generation. Also, in 2018, Saravanan et al. [20] investigated pressure drop and heat transfer in a micro pin fin heat sink and a micro channel pin fin heat sink with different pin shapes including circular and square. In this study pin fins with staggered arrangement were studied numerically in Reynolds numbers ranging 100 to 900 . They also particularly focused on the flow pattern around the pin fins and showed that the presence of secondary vortices around the square pins in the micro channel contributes to better heat dissipation compared to the circular ones.

In the present study, a heat sink subjected to a heat flux exerted to a certain part of its base is considered. While there has been much research carried out on this subject, optimizing a micro pin fin heat sink by studying different pin fin cross sections and other geometrical parameters in terms of thermal and hydraulic performance has not been studied before. 
Therefore, the main idea in this work is to achieve the suitable geometry, dimensions, and location of the pins in order to enhance the thermal performance in the interest of improving heat dissipation in the heated region and making the temperature distribution uniform. To achieve these purposes, three geometries including circular, airfoil and elliptical in four different sizes are investigated and compared. Considering the fact that hydraulic and thermal performance are functions of thermophysical characteristics of fluid, velocity and flow regime, Reynolds number is used as a dimensionless parameter to consider these items. The results are presented as a function of Reynolds number in the range of 2730 to 6300 . On the other hand, inserting the pins increases turbulence intensity, thus causing a pressure drop and lowering the hydraulic performance. It is necessary to consider these effects on the hydraulic and thermal performance simultaneously to reach an optimal geometry. So that, variables such as thermal resistance, maximum temperature, and Nusselt number are considered to analyze the thermal performance. Also, pressure drop and friction coefficient are presented to examine the hydraulic performance.

\section{SIMULATION}

\subsection{Geometry}

(a)

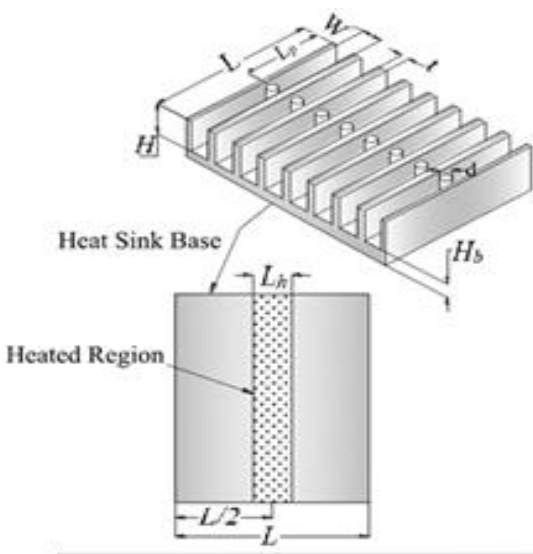

(b)

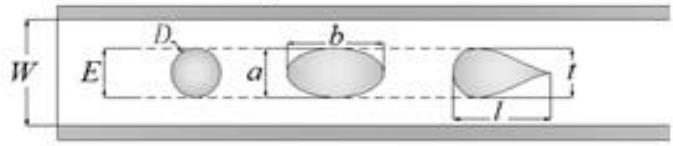

Figure 1. Schematic diagrams: (a) Plate-pin fin heat sink with the heat flux applied; (b) The pin fins geometric parameters

Figure 1a depicts the studied heat sink and the region subjected to the heat flux which is a strip of channel's bottom surface at the center of it, having a surface equal to one fifth of the whole base area. In order to enhance the thermal dissipation in the heated region, the pin fin is placed right in the center of the heated area. A dimensionless parameter, E/W, is presented to investigate the influence of pin fin dimensions, in which $\mathrm{E}$ is defined as the lateral dimension of the pin fin normal to flow direction (equal to diameter in the case of cylindrical pins) and $\mathrm{W}$ is the width of the channel as illustrated in Figure 1a. The geometric properties of the heat sink are tabulated in Table 1. Given the resemblance of the channels, only one of them has been considered as the computational domain and its schematics is presented in Figure 2. The boundary conditions are explained in detail in the following section. Additionally, in order to improve the hydraulic and thermal characteristics of the heat sink, different pin cross sections including circular, elliptical and airfoil, has been examined and the geometric details and dimensions are presented in Figure 1b and Table 2. As presented in Table 2, various values for $\mathrm{E} / \mathrm{W}$ ratio including $0.3,0.4,0.5$, and 0.6 have been considered for this study.

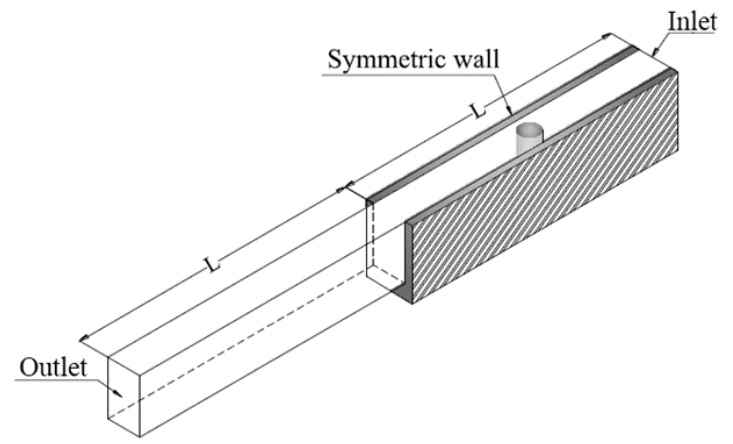

Figure 2. Computational domain

Table 1. The heat sink dimensions

\begin{tabular}{ccc}
\hline Parameter & Symbol & Value \\
\hline Heat sink length in direction of flow & $L$ & $50 \mathrm{~mm}$ \\
Number of pin fins & $N$ & 9 numbers \\
Heat sink base thickness & $H_{b}$ & $3 \mathrm{~mm}$ \\
Heated region length & $L_{h}$ & $10 \mathrm{~mm}$ \\
Lateral dimension of pin fin normal to & $E$ & $1.5,2,2.5$, \\
flow direction & & $3 \mathrm{~mm}$ \\
Plate/pin fin height & $H f$ & $10 \mathrm{~mm}$ \\
Channel width & $W$ & $5 \mathrm{~mm}$ \\
Wall thickness & $t$ & $1.5 \mathrm{~mm}$ \\
\hline
\end{tabular}

Table 2. Geometric properties and dimensions of the pin fins (mm)

\begin{tabular}{cccccc}
\multirow{2}{*}{ Geometry } & \multirow{2}{*}{ Parameter } & \multicolumn{4}{c}{ Geometric Ratio $\boldsymbol{E} / \boldsymbol{W}$} \\
\cline { 2 - 6 } & & 0.3 & 0.4 & 0.5 & 0.6 \\
\hline \multirow{2}{*}{ Circular } & $D$ & 1.5 & 2 & 2.5 & 3 \\
\cline { 2 - 6 } Elliptic & $a$ & 1.5 & 2 & 2.5 & 3 \\
& $b$ & 3 & 4 & 5 & 6 \\
\cline { 2 - 6 } Airfoil & $l$ & 1.5 & 2 & 2.5 & 3 \\
& $t$ & 3 & 4 & 5 & 6
\end{tabular}

\subsection{Governing equations and numerical method}

The following equations govern the conservation of mass and momentum for compressible flow written in an averaged form [21]:

$\frac{\partial \overline{u_{l}}}{\partial x_{i}}=0$

$\rho \bar{u}_{j} \frac{\partial \bar{u}_{i}}{\partial x_{i}}=-\frac{\partial \bar{p}}{\partial x_{i}}+\frac{\partial}{\partial x_{j}}\left[\mu\left(\frac{\partial \bar{u}_{i}}{\partial x_{j}}+\frac{\partial \bar{u}_{j}}{\partial x_{i}}\right)-\rho \overline{u_{\imath} u_{J}}\right]$

where $\rho, \mu, \bar{p}$ and $\bar{u}$ represent cooling fluid density, dynamic viscosity coefficient, mean pressure and mean velocity, respectively. Energy equation can be stated in an averaged form as follows [21]:

$\rho \bar{u}_{j} \frac{\partial \bar{T}}{\partial x_{j}}=\frac{\partial}{\partial x_{j}}\left[\left(\frac{\mu}{\sigma_{l}}+\frac{\mu_{t}}{\sigma_{t}}\right) \frac{\partial \bar{T}}{\partial x_{j}}\right]$ 
where $\bar{T}$ represents fluid mean temperature, and $\mu$ and $\mu_{t}$ are the dynamic viscosity of laminar and turbulent flow, respectively. $\sigma_{l}$ and $\sigma_{t}$ are empirical constants for the laminar and turbulent flow, respectively, which depend on the turbulence model adopted.

Computational fluid dynamics (CFD) has proven to be a reliable resolution to these equations and has been emplyed successfully by other researchers [22-26]. A CFD model was created and developed in order to approch the problem. In this model the fluid flow is considered three dimensional and assumed to be turbulent, incompressible and steady. Calculations are based on constant thermodynamic properties and negligible radiation heat transfer. Above-mentioned equations are discretized using finite volume approach and solved using SIMPLE (semi-implicit method for pressurelinked equation consistent) algorithm. Also, two equation k- $\varepsilon$ RNG model is applied to simulate turbulence. The open source software OpenFOAM is employed for the simulations. Coupled and no-slip boundary condition is used for solid fluid interface to simulate their conjugate heat transfer and dynamic behavior, respectively. Velocity inlet and pressure outlet are considered as the boundary conditions at channel inlet and outlet, respectively. Inlet temperature is equal to surrounding air temperature. On Symmetric walls, all parameters have zero flux and it is applied using symmetry boundary condition. All other surfaces except heating area are adiabatic.

\subsection{Introducing parameters}

In order to examine the heat sink performance, thermal resistance and Nusselt number need to be considered. Hence, the thermal resistance of the heat sink can be written as follows:

$R_{t h}=\frac{\Delta T}{Q}$

where $\mathrm{Q}$ and $\Delta \mathrm{T}$ denote the dissipated heat from the heat sink and temperature difference, respectively. $\Delta \mathrm{T}$ has been defined in two different forms by various researchers. Yu et al. [9], Zhou and Catton [22], and Yuan et al. [8] defined this parameter as the difference of the highest temperature on the base of the heat sink and the coolant temperature at the heat sink inlet, while Jonsson and Moshfegh [28] considered this parameter as the difference between the average temperature on the heat sink base and the inlet air. In this study, the definition of $\mathrm{Yu}$, Zhou and Yuan has been used.

Nusselt number, which is related to the convective heat transfer properties, indicates the dimensionless temperature slope and can be stated as:

$N u=\frac{h D_{H}}{k_{f}}$

where $k_{f}, h$ and $D_{H}$ represent conduction coefficient, mean convection coefficient and hydraulic diameter of micro channel, respectively. These parameters can be defined as a function of heat sink dimensions ( $\mathrm{W}$ and $\mathrm{H}$ ) as follows:

$D_{H}=2 W \cdot H /(W+H)$

$h=\frac{Q}{A_{C}\left(T_{S a v g}-T_{\propto}\right)}$ where $Q, A_{C}, T_{S \text { avg }}$ and $T_{\propto}$ are heat transfer rate at the surface, cooled surface, the average temperature of the surface and the channel inlet flow, respectively. Reynolds number is defined as:

$R e=\frac{\text { inertia forces }}{\text { viscous forces }}=\frac{\rho u_{\text {in }} \delta}{\mu}$

where $u_{\text {in }}$ denotes inlet air velocity and $\delta$ is characteristic length equal to the hydraulic diameter of flow section. Pressure drop and friction coefficient were studied in order to investigate the hydraulic performance of the heat sink. The friction coefficient can be defined as follows, in which, $\Delta \mathrm{P}$ and $\mathrm{L}$ are the pressure drop and the channel length, respectively [27].

$f=\frac{\Delta P}{0.5 \rho u_{\text {in }}^{2}} \cdot \frac{D_{H}}{4 L}$

Regarding the heat sink performance, overall performance coefficient is defined, in which both thermal and hydraulic parameters are included:

$\eta_{e f f}=\frac{N u / N u_{\propto}}{\left(f / f_{\propto}\right)^{1 / 3}}$

where $N u_{\propto}$ and $f_{\propto}$ are reference parameters, Nusselt number and friction coefficient, respectively, in a plate fin channel with identical dimensions subjected to a fully developed flow. These parameters can be derived from Dittus-Boelter and Blasius equations, respectively [1]:

$N u_{\propto}=0.023 R e^{0.8} \operatorname{Pr}^{0.4}$
$f_{\propto}=0.079 R e^{-0.25}$

\subsection{Validation and grid study}

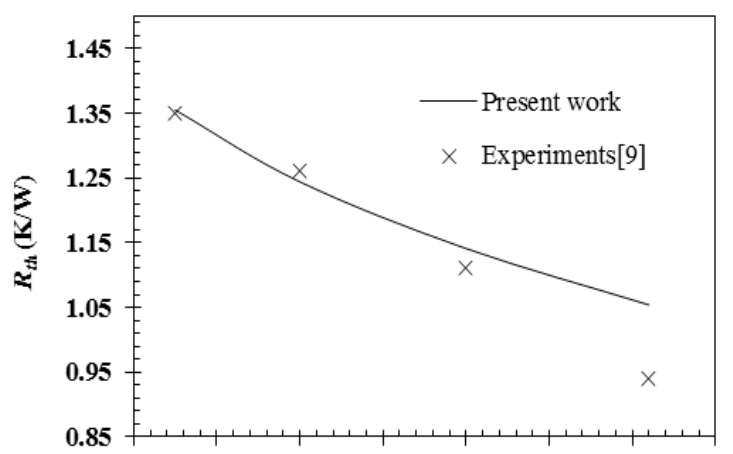

Figure 3. Comparison of simulation and experimental results for thermal resistance

The proposed results by $\mathrm{Yu}$ et al. [2] in 2005 for a microchannel heat sink under forced convective heat transfer with turbulent flow have been considered in order to validate the accuracy of the implemented numerical method. The channel inlet velocity, as well as the outlet pressure, have been assumed to be uniform and the no-slip condition has been applied to the walls. Also, the base of the heat sink is subjected to a constant heat flux. The thermal resistance of the heat sink is presented in Figure 3 within the range of 6.5 to $12.2 \mathrm{~m} / \mathrm{s}$ with an average error percentage of $3.5 \%$. Also, the pressure drop along the channels for the same range of velocities is presented in Figure 4. Analyzing the results show that average 
error percentage for the pressure drop is $7.3 \%$. Despite the influence of temperature on physical characteristics of the fluid, they have been assumed to be constant. This item could be a source of error in the simulation process. The final mesh grid is shown in Figure 5.

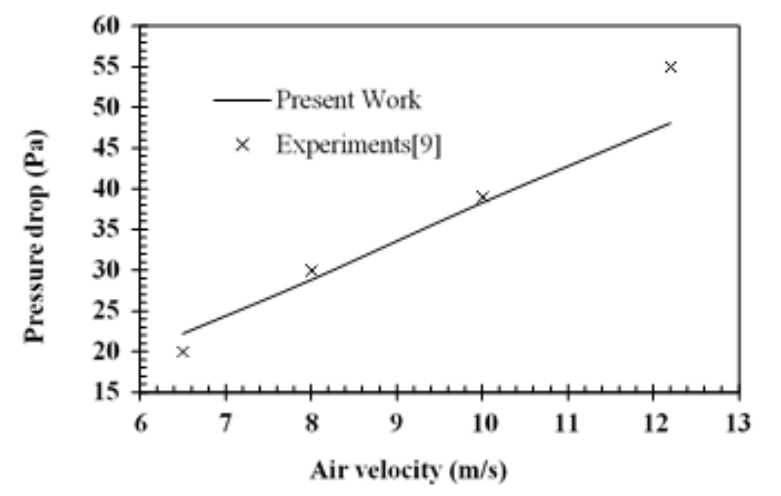

Figure 4. Comparison of simulation and experimental results for pressure drop

Table 3. Trend of thermal hydraulic analysis results versus number of cells

\begin{tabular}{cccc}
\cline { 2 - 4 } & Step 1 & Step 2 & Step 3 \\
\hline Number of Grids & 440,000 & 879,000 & $1,079,000$ \\
\hline Thermal Resistance (K/W) & 0.975 & 0.809 & 0.833 \\
\hline Pressure Drop (Pa) & 70.27 & 76.52 & 76.2 \\
\hline $\begin{array}{c}\text { Thermal Resistance } \\
\text { Variation (\%) }\end{array}$ & - & 20.51 & 2.88 \\
\hline $\begin{array}{c}\text { Pressure Drop Variation } \\
(\%)\end{array}$ & - & 8.17 & 0.42 \\
\hline
\end{tabular}

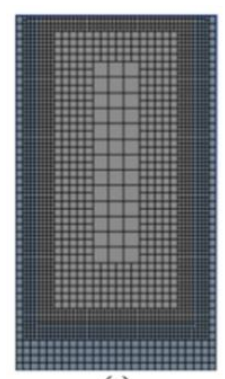

(a)

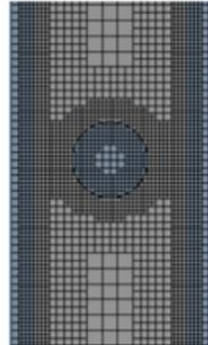

(b)

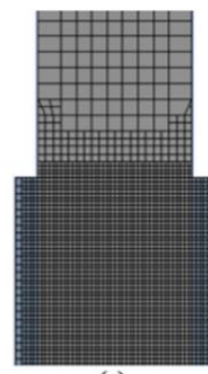

(c)
Figure 5. Mesh distribution a) inlet; b) around the pin fin (top view); c) channel outlet (top view)

\section{RESULTS AND DISCUSSION}

\subsection{Effect of inserting pins}

In order to investigate the heat sink performance, the thermal resistance has been presented in Figure 6 for both plate and pin fin heat sinks as a function of the Reynolds number for four various sizes of the pin fin. The results are compared with the smaller pin with the geometric ratio $(E / W)$ equal to 0.3 , which has a minor effect on the hydraulic and thermal performance. The results show that the thermal resistance of the heat sink has been diminished by $33.4 \%$ on average by inserting pins. In addition, increasing the geometric ratio of the pin from 0.3 to 0.4 decreases the thermal resistance by $4.6 \%$ on average; whereas, further increasing the parameter from 0.4 to 0.5 decreases the thermal resistance by $3.8 \%$ on average.

Inserting a pin into the heat sink channel increases the heat transfer area, thus improving the convection process. Moreover, placing a circular pin in flow path generates a wake region downstream and due to the no-slip condition on the walls and variation in the cross section of the flow, velocity gradients are intensified, increasing fluctuating components of the velocity. These components continuously transfer the momentum between the adjacent layers that increases the turbulence of flow and heightens the heat transfer rate. Accordingly, using a pin with a larger diameter increases the interface between the cooling fluid and the walls as well as the turbulence caused by the effect of the walls. So that, the created wake and the resulted turbulence are amplified. On the other hand, the flow velocity is another determining factor to convective heat transfer mechanism. Therefore, implementing both methods, inserting pins and increasing the fluid velocity, improves the thermal performance. In order to examine the hydraulic performance, the pressure drop along the heat sink is illustrated as a function of Reynolds number in Figure 7. The rise in the pressure drop reaches over $115 \%$ for the geometric ratio of 0.3 and the Reynolds number of 2730 in the presence of the pins. Raising the Reynolds number to 6300 results in a drastic increase in the pressure drop as much as $165 \%$ and the trend continues at higher Reynolds numbers as well. For the Reynolds number of 6300 , the pressure drop variates by changing the geometric ratio as $14 \%$ by changing $E / W$ from 0.3 to $0.4,28 \%$ for $E / W$ from 0.4 to 0.5 and $45 \%$ for $E / W$ from 0.5 to 0.6 . As mentioned above, adding pins increases the turbulence and accelerates the flow due to the decrease in the flow cross section, thus causing more pressure drop. Using larger pins is clearly more deteriorating, raising the friction coefficient and the pressure drop.

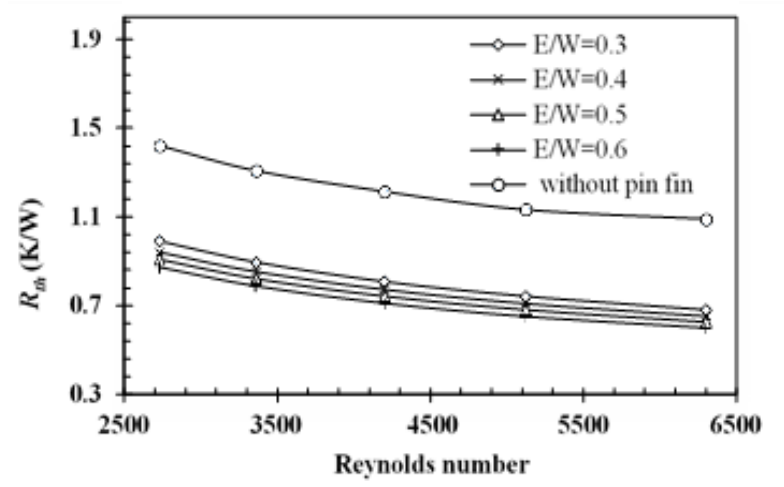

Figure 6. Thermal resistance of the heat sink with circular pins

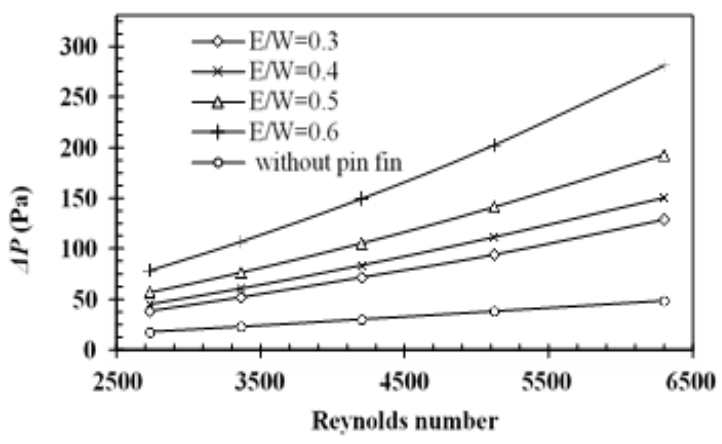

Figure 7. Pressure drop along the heat sink with circular pins 
As it is shown in Figures 6 and 7, thermal resistance diminishes by increasing the Reynolds number of the flow, while the pressure drop along the channel is subjected to a drastic increase. So that, the proper geometry and performance conditions need to be determined with respect to factors such as required cooling power, efficiency, and maximum allowable temperature. In order to consider all these variables simultaneously, the heat sink performance coefficient is presented as a function of Reynolds number in Figure 8. Given the approximate linear behavior of the presented curves for the circular geometry and the similar line slopes for them, one can suggest that for all the geometries studied, the performance coefficient declines by $3 \%$ per 500 units increment of Reynolds number. According to Figure 8, decreasing the pin diameter improves the heat sink performance. Therefore, the heat sink would be at the lowest performance condition for $E / W$ equal to 0.6 . Diminishing this parameter from 0.6 to 0.5 enhances the performance coefficient by $4.26 \%$. In the case of $E / W$ equal to 0.6 or 0.4 , the results for the performance coefficient are so close that decreasing it from 0.4 to 0.3 leads to a slight improvement of $0.57 \%$. Given this fact and also higher manufacturing costs for such small pin fins, $E / W$ values less than 0.3 have not been considered for this study.

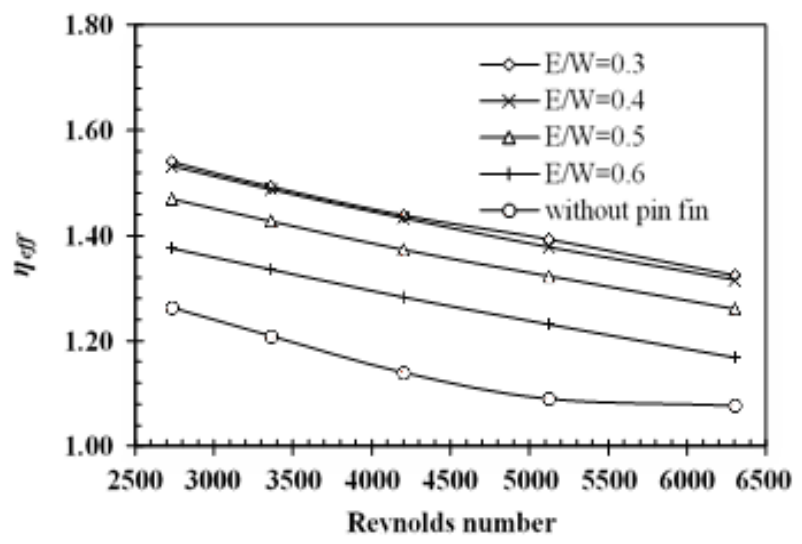

Figure 8. Effect of pin fin dimensions on the coefficient of performance

\subsection{Effect of pin location}

In order to investigate the location of the pin on the heat sink, a dimensionless parameter, $L^{*}$, is defined, which denotes the axial distance of the center of the pin from the center of the heated area:

$L^{*}=\frac{2\left(\frac{L}{2}-L_{P}\right)}{L}$

As shown in Figure $1 a, L$ and $L p$ represent the heat sink length and the distance of the center of the pin from the channel inlet, respectively, where $L^{*}$ equal to zero signifies placing the pin in the center of the heat sink and $L^{*}$ equal to one indicates a pin located in the center of the channel inlet. This parameter has been investigated for values of 0 to 0.6 . Thermodynamic behavior of the heat sink for larger $\mathrm{L}^{*}$ value is independent (or is the same as $\mathrm{L}^{*}=0.6$ ).

Thermal resistance is depicted in Figure 9 for E/W of 0.3 at three different Reynolds numbers of 2730, 3360 and 4200. For the geometry ratio of 0.3 , the curves of the thermal resistance versus the dimensionless distance have two minimum points. So that, when the pin is located exactly on the heated area, thermal resistance is minimized and by increasing the distance, thermal performance is affected slightly, while by reaching to $L^{*}$ of 0.4 , there will be another minimum point for thermal resistance. However, the sensitivity of the thermal resistance to $L^{*}$ is not significant, resulting in only $1.4 \%$ improvement at most, true for all the Reynolds numbers studied. In fact, locating the pin in the center of the heated region increases the heat transfer surface of it. Therefore, by increasing the contact surface where the temperature difference between the surface and the fluid is maximum, the convective heat transfer is improved and by increasing the distance of the pin fin from the heated region, the temperature difference diminishes, affecting the thermal performance. On the other hand, in a certain distance, the turbulence caused by the pin is increased to its maximum, enhancing the heat transfer rate. Accordingly, when there is a maximum contact surface between the turbulent area and the heated region, heat dissipation would improve. Noting the presented diagrams (for the geometry ratio of 0.3 ), setting the pin where $L^{*}$ is 0.4 , increases the turbulence effects to its maximum amount and diminishes the thermal resistance, while moving it further deprives it of turbulence benefits and weakens the heat rejection process.

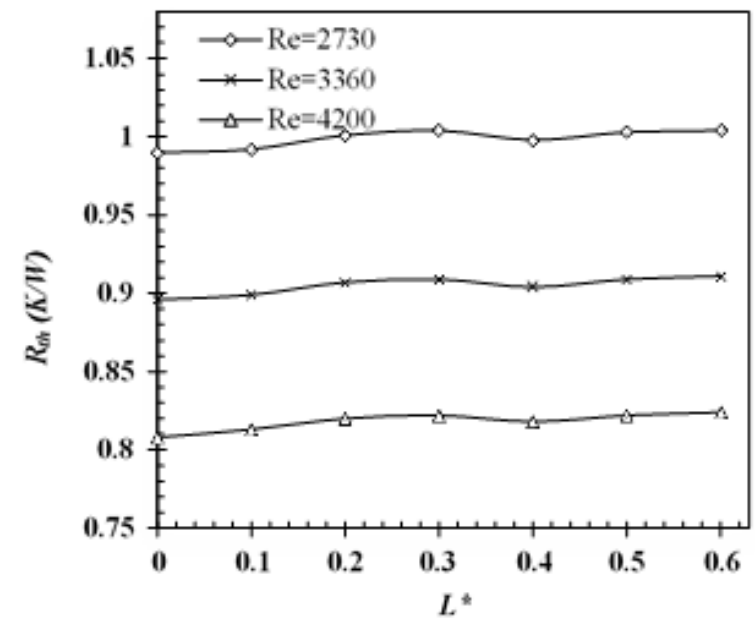

Figure 9. Effect of pin fin location on thermal resistance $(\mathrm{E} / \mathrm{W}=0.3)$

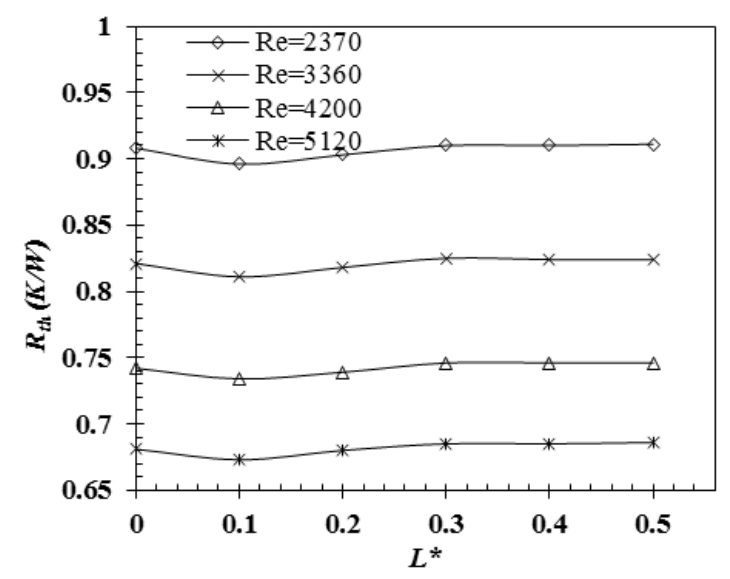

Figure 10. Effect of pin fin location on thermal resistance $(\mathrm{E} / \mathrm{W}=0.5)$

The thermal resistance is illustrated in Figure 10 for $E / W$ of 0.5 and three Reynolds numbers of 2730, 3360 and 4200 . For $E / W$ equal to 0.5 and all the Reynolds numbers studied, the 
minimum thermal resistance occurs at $L^{*}$ of 0.1 , having about $1.3 \%$ less thermal resistance compared to the case in which the pin fin is located in the center of the heated region. In fact, placing the pin in this point generates the turbulence precisely on the heated area. On the other hand, due to the rather short distance from the heated area, there is a high temperature difference between the surface and the coolant fluid. Thus, the heat transfer rate and the thermal performance are higher compared to those of other cases.

\subsection{Effect of inserting non-circular pins}

Implementing the circular pin fins in the center of the channel considerably affects the hydraulic performance by generating a wake region. On the other hand, the heat transfer surface, which has a great impact on the thermal performance, depends on the pin geometry. Hence, other geometries including elliptic and airfoil have been studied. In this section, the Nusselt number and the friction coefficient are presented to analyze the thermal and hydraulic performance of the heat sink with non-circular pins.

\subsubsection{Elliptic geometry}

Nusselt number versus Reynolds number is depicted in Figure 11 for various values of $E / W$ in order to investigate the thermal performance of the elliptic pin fin heat sink. $E / W$ is clearly an effective parameter to the thermal performance. By increasing $E / W$ from 0.3 to 0.4 , Nusselt number rises by 5.84 $\%$ on average and further increasing the geometry ratio from 0.5 to 0.6 and from 0.6 to 0.7 results in $7.7 \%$ rise in Nusselt number.

In fact, using pins with larger diameters increases the heat transfer surface, consequently improving the heat transfer rate. In addition, the turbulence caused by the walls and consequently the wake region will be expanded. Thus, using a larger pin increases the fluctuating components of the mass transfer velocity which results in a higher heat transfer rate in fluid layers. These phenomena diminish thermal resistance as well as the maximum temperature at the pin base. Besides, for the same $E / W$ values, the elliptic pins have more contact surface for convection compared to that for circular ones. Moreover, due to the elliptic shape of the pin, the flow passages created on both sides of it will be further extended, having more impact on the thermal performance. Therefore, changing the geometric ratio has a greater impact on the thermal performance compared with the circular pins.

In order to examine the hydraulic performance, the friction coefficient is presented in Figure 12. By changing the ratio of $E / W$ from 0.3 to 0.4 , there will be $20.01 \%$ increase in friction coefficient and by changing it from 0.4 to 0.5 , the friction coefficient increases by $35.16 \%$. Also, augmenting the geometric ratio of the pin from 0.5 to 0.6 results in an increase in friction coefficient by $48.99 \%$. Evidently, $E / W$ has a great impact on the hydraulic performance and increasing this ratio increases the friction coefficient drastically.

In other words, using the pins with a larger ratio of $E / W$, increases the contact surface and diminishes the flow passage cross section. Hence, the variation in the velocity components is amplified and momentum transfer between the fluid layers as well as the pressure drop consequently increase. Besides, increasing the geometric ratio results in a more extended wake region downstream, thus causing more pressure drop along the heat sink channel.

Based on Figure 13, similar to the circular pins, the elliptical pins also provide a higher overall performance coefficient with rather smaller values of $E / W$ as increasing the geometric ratio from 0.4 to 0.5 and from 0.5 to 0.6 results in an average decrease of $2.2 \%$ and $6.17 \%$ in overall performance coefficient, respectively. Also, the results imply that the overall performance coefficient of the heat sink is not subjected to a major difference for different geometric ratios of 0.3 and 0.4 , as increasing this ratio from 0.3 to 0.4 leads to only $0.4 \%$ decrease in the overall performance coefficient. Therefore, given the close values for the overall performance of these geometries, in addition to thermal requirements, pump requirements, technology, and manufacturing costs, also need to be considered in order to attain an optimal choice.

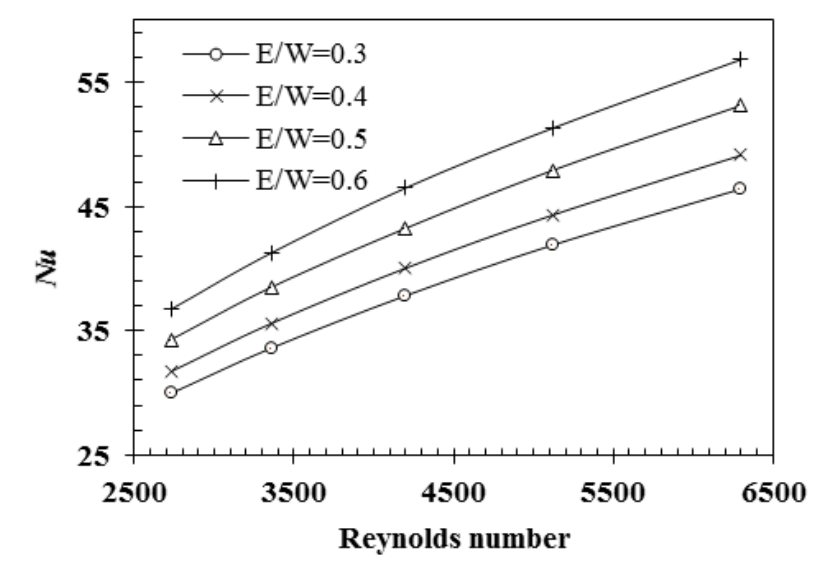

Figure 11. Nusselt number for the heat sink with elliptic pins

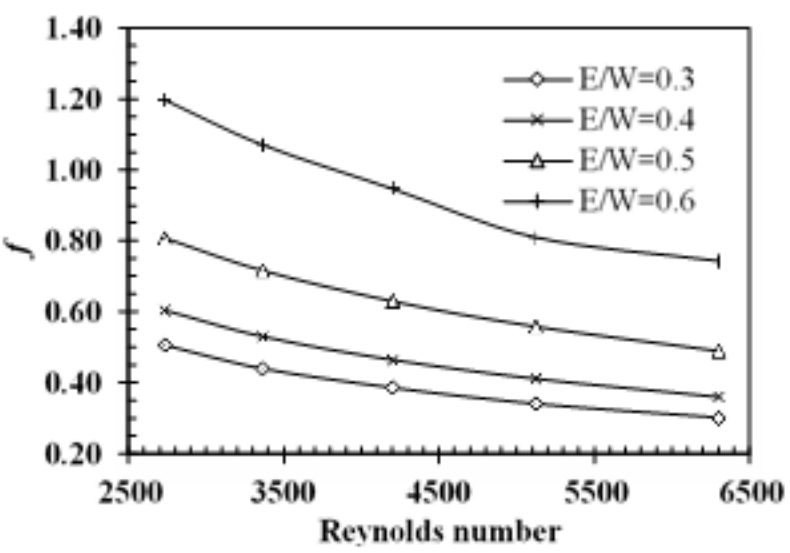

Figure 12. Friction coefficient of the heat sink with elliptic pins

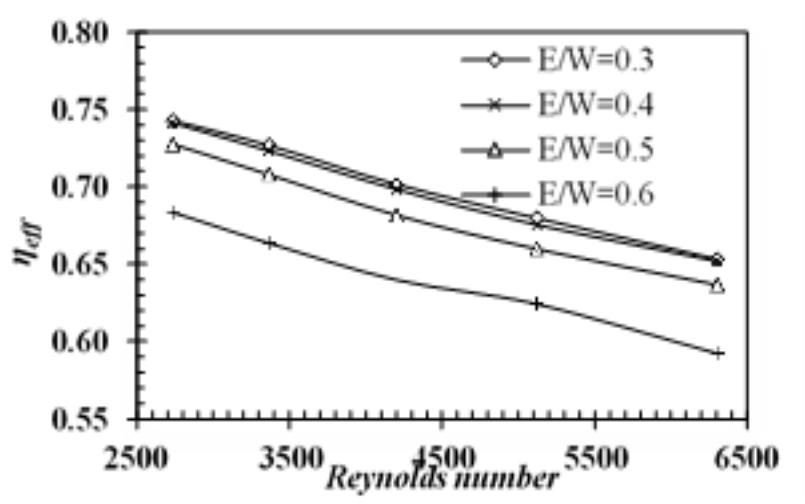

Figure 13. Effect of elliptic pin fin dimensions on coefficient of performance 


\subsubsection{Airfoil geometry}

Airfoil is a streamlined body, so it is expected that using this geometry modifies the flow pattern around the pin, thus a higher hydraulic performance and subsequently a higher performance coefficient would be achieved. In order to investigate this item, Figure 14 is presented and analyzed. Similar to the other cross sections studied, the airfoil pin has a better thermal performance using larger $E / W$ values. So that, increasing this parameter from 0.3 to 0.4 , increases the Nusselt number by $12.07 \%$, averagely. For two various pins with $E / W$ values equal to 0.4 and 0.5 , the thermal parameters are about the same and for a pin with a larger diameter, the Nusselt number rises by $3.25 \%$, averagely. As it is depicted in Figure 15 , employing a pin with a geometric ratio of 0.6 , impacts the thermal performance to a great extent as compared to the geometric ratio of 0.5 , the Nusselt number is increased by 6.89 $\%$.

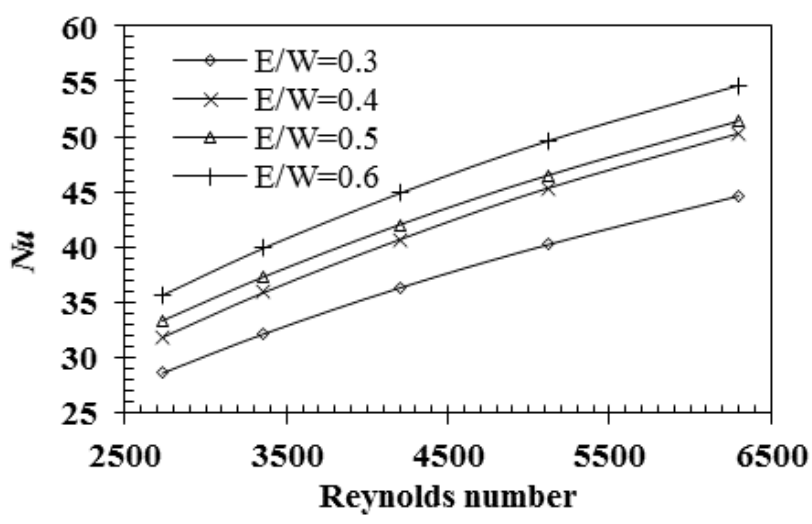

Figure 14. Nusselt number for the heat sink with airfoil pins

Similar to the circular and the elliptic geometries, using a larger pin extends the heat transfer surface. In addition, there is more influence on the flow passage around the pin, compared to the circular pin. As mentioned above, these items have a positive effect on thermal performance. For the geometric ratios of 0.4 and 0.5 , flow separation occurs on the airfoil and the wake region is expanded, extremely increasing the Nusselt number.

According to Figure 15, which represents the friction coefficient for a heat sink with airfoil pins, employing this type of pin with $E / W$ of 0.6 significantly impacts the hydraulic performance. However, the extent of this effect depends on the Reynolds number, as diminishing $E / W$ from 0.6 to 0.5 causes the pressure drop and the friction coefficient to decrease by $31.43 \%$ on average. By further decreasing this ratio from 0.5 to 0.4 and from 0.4 to 0.3 , the pressure drop and the friction coefficient decline by $15.32 \%$ and $19.83 \%$, respectively. Increasing the geometric ratio makes the flow passage created around the pin narrower, thus increasing the local velocity, the pressure drop and the friction coefficient to a great extent. As it is shown in Figure 16, the highest performance coefficients correspond to $E / W$ of $0.5,0.4$ and 0.3 , respectively, while the lowest one is for $E / W$ equal to 0.6 . For $E / W$ equal to 0.5 and 0.4 at low Reynolds numbers, overall performance coefficients are not significantly varied, as at the Reynolds number of 2730 , there is only $0.64 \%$ improvement in the overall performance by diminishing the geometric ratio. The efficacy of this ratio is more highlighted as the Reynolds number increases, where for the Reynolds number of 6300 , the improvement reaches $3.74 \%$. As $E / W$ declines from 0.4 to 0.3 , the performance coefficient of the heat sink declines by 3.94 $\%$, on average. At high Reynolds numbers and $E / W$ equal to 0.3 and 0.5 , the results for the performance coefficient are about the same. Also, when $E / W$ equals 0.3 , the variation in the performance coefficient is $8 \%$ on average, compared to that for $E / W$ of 0.6 .

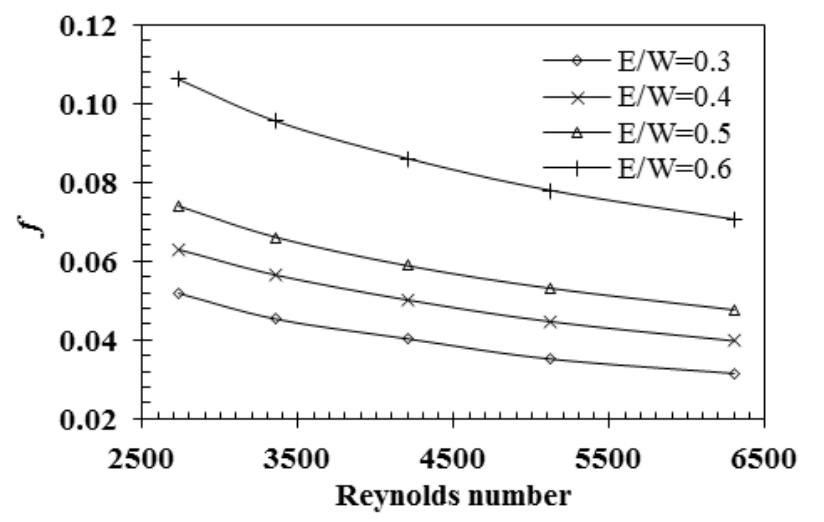

Figure 15. Friction coefficient of the heat sink with airfoil pins

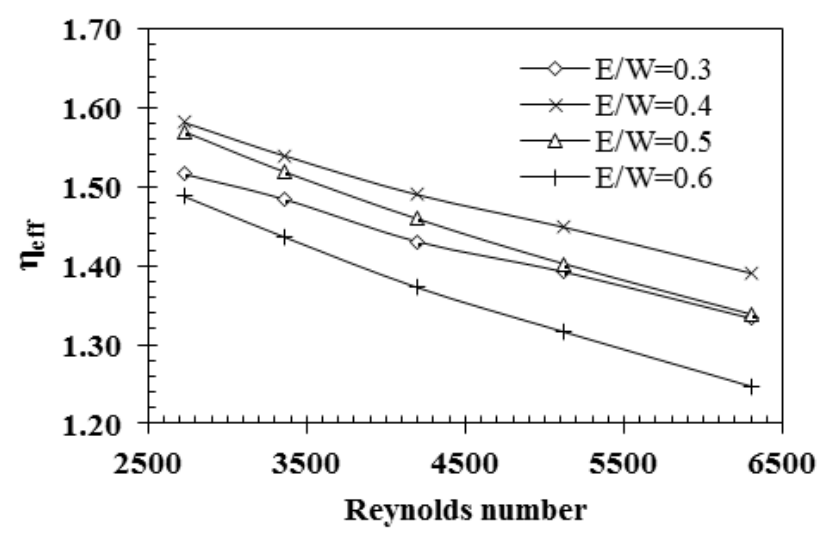

Figure 16. Effect of airfoil pin dimensions on the coefficient of performance

\subsection{Different geometries with equal geometric ratios}

In order to attain an optimal point, it is necessary to consider the thermal and hydraulic performance as a function of the pin geometry and operating conditions. Thus, three different geometries including circular, elliptic and airfoil, have been examined within a range of Reynolds numbers, 2730 to 6300 , and the results are analyzed for the geometric ratio of 0.5 .

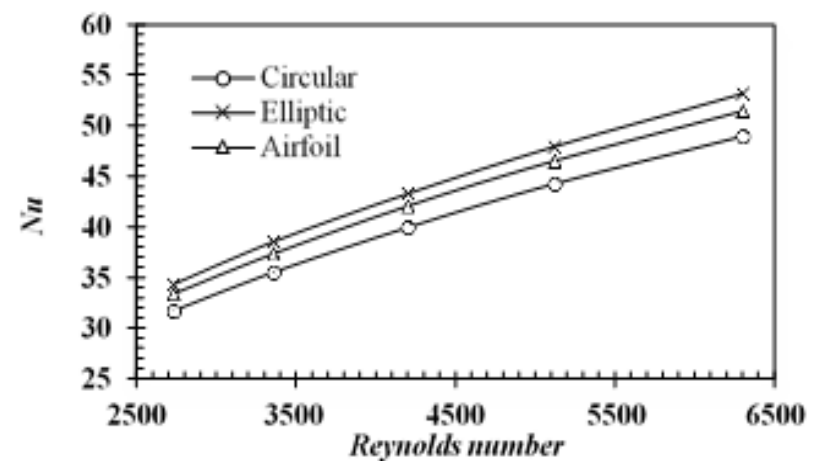

Figure 17. Effect of pin fin geometry on Nusselt number $(\mathrm{E} / \mathrm{W}=0.5)$ 


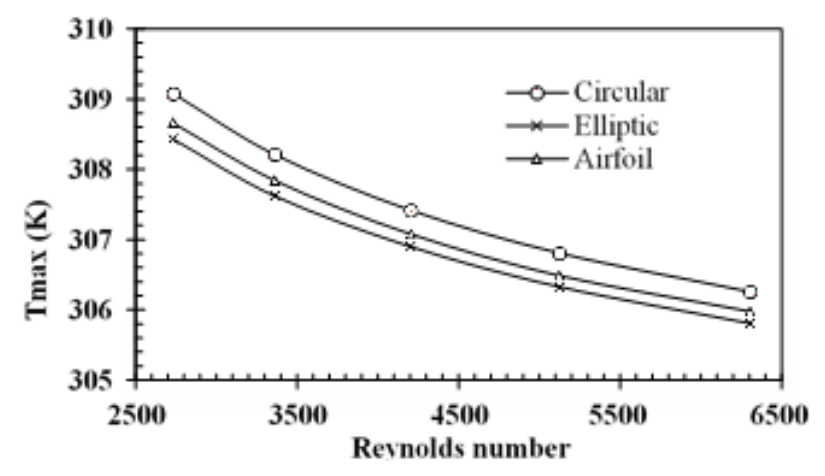

Figure 18. Maximum Temperature of the heat sink base with circular, airfoil and elliptic pin fin $(\mathrm{E} / \mathrm{W}=0.5)$

Figure 17 depicts the Nusselt number for the three different geometries. The results indicate that the highest and the lowest values of Nusselt number correspond to the elliptic and the circular geometries, respectively. In addition, in comparison with the circular pin, airfoil and elliptic geometries improve the Nusselt number by $5.2 \%$ and $8.4 \%$, respectively. Apparently, the heat transfer surface is the most important factor for improving the thermal performance in these operating conditions. Hence, elliptic, airfoil and circular geometries, having the most to the least heat transfer surface, respectively, provide the highest to the lowest thermal performance, respectively. The maximum temperature at the base of the heat sink, which is a key parameter to design, is presented in Figure 18. The results indicate that by using elliptic and airfoil shapes for the pin, the temperature distribution is enhanced at the base of the heat sink. Contours of the temperature distribution at the base of the heat sink, presented in Figure 19, strongly approve of this fact. Also, the pressure and velocity magnitude contours are presented for comparison in Figure 20 and Figure 21, respectively.

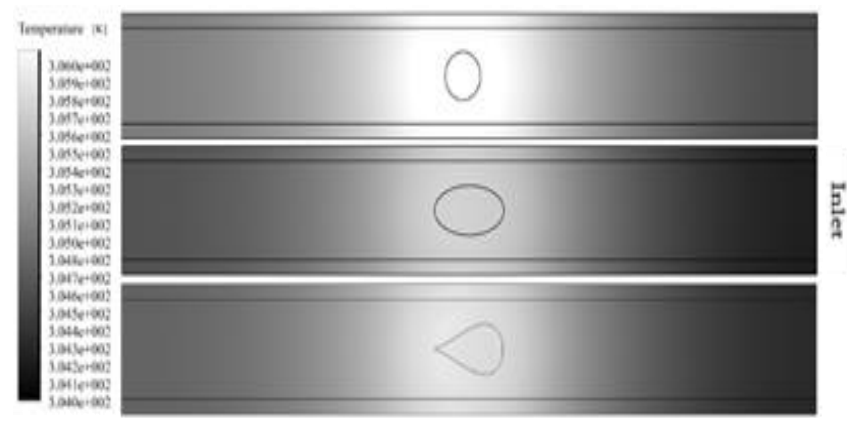

Figure 19. Temperature contour at the heat sink base for different pin fin geometries $(\mathrm{E} / \mathrm{W}=0.5, \mathrm{Re}=6300)$

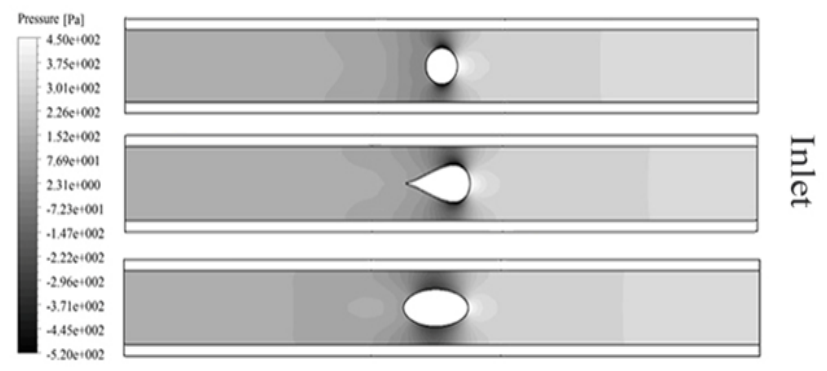

Figure 20. Pressure contour at the heat sink base for different pin fin geometries $((\mathrm{E} / \mathrm{W}=0.5, \mathrm{Re}=6300)$

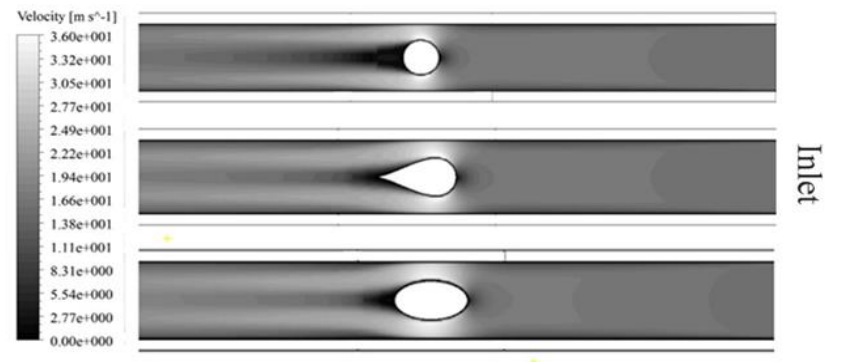

Figure 21. Pressure contour at the heat sink base for different pin fin geometries $((\mathrm{E} / \mathrm{W}=0.5, \mathrm{Re}=6300)$

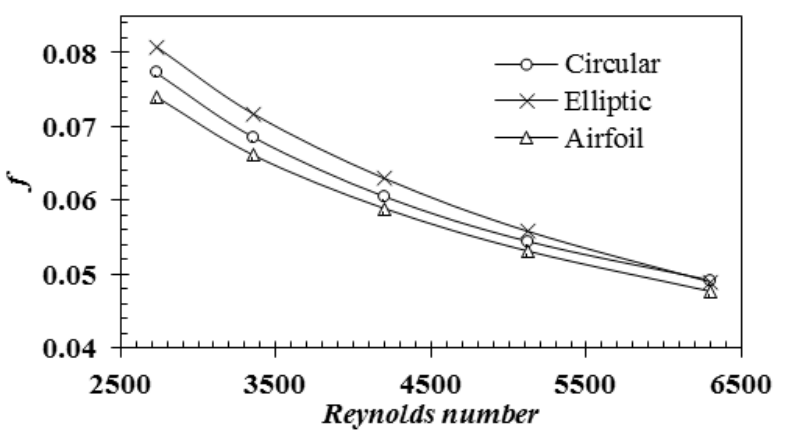

Figure 22. Effect of pin fin geometry on friction factor $(\mathrm{E} / \mathrm{W}=0.5)$

In order to explore the hydraulic performance of the heat sink, friction coefficient parameter is presented in Figure 22. Elliptic, circular and airfoil geometries have the highest to the lowest values of friction coefficient, respectively. At low Reynolds numbers there is a significant difference in the hydraulic performance of different geometries, while as the Reynolds number increases, the difference declines.

For the lowest Reynolds number studied, 2730, elliptic pin increases the friction coefficient by $4.6 \%$ compared to the circular one, while the airfoil pin enhances the hydraulic performance and reduces the friction coefficient by $4.2 \%$ compared to the circular pin. The streamline patterns for the three geometries studied (for $E / W$ of 0.5 and the Reynolds number of 6300) are presented in Figure 23. For elliptic geometry, the reduction of the flow cross section and consequently the increase in the velocity occurs in a more extended area; therefore, due to the no-slip condition, the fluid layers are more affected by the walls, increasing the velocity gradients in fluid layers. Hence, employing these types of pins increases the pressure drop along the channel, while for the two other geometries, given the relatively shorter length of the affected flow passage, the effect of Reynolds stress is reduced. In addition, having a streamlined shape, airfoil modifies the flow pattern, reducing the pressure drop behind the pin.

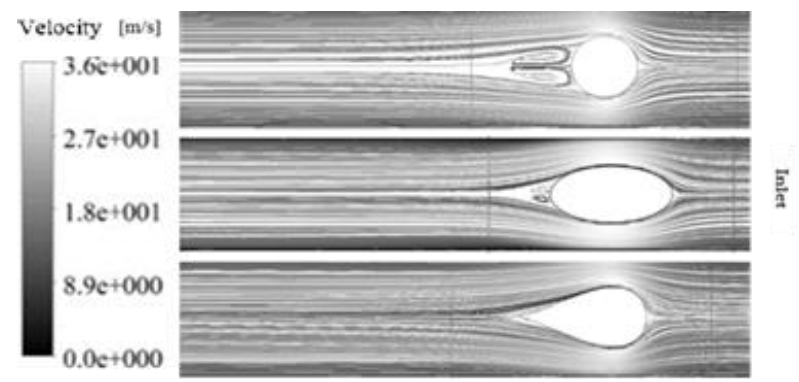

Figure 23. Streamline patterns for different pin geometries $(\mathrm{E} / \mathrm{W}=0.5, \mathrm{Re}=6300)$ 
In order to compare different heat sinks in terms of the overall performance, Figure 24 is presented. As one can note, the overall performance coefficient of the heat sink depends on shape of the pin fin employed. Accordingly, the elliptic pin provides a higher overall performance coefficient, $7.1 \%$ greater than that of the circular one. Provided values for the airfoil pin is notably close to those of circular one, as at low Reynolds numbers the results are about the same, while by increasing this number, the difference increases. However, this difference is still not significant as for the Reynolds number of 6300 , it reaches up to $2.4 \%$.

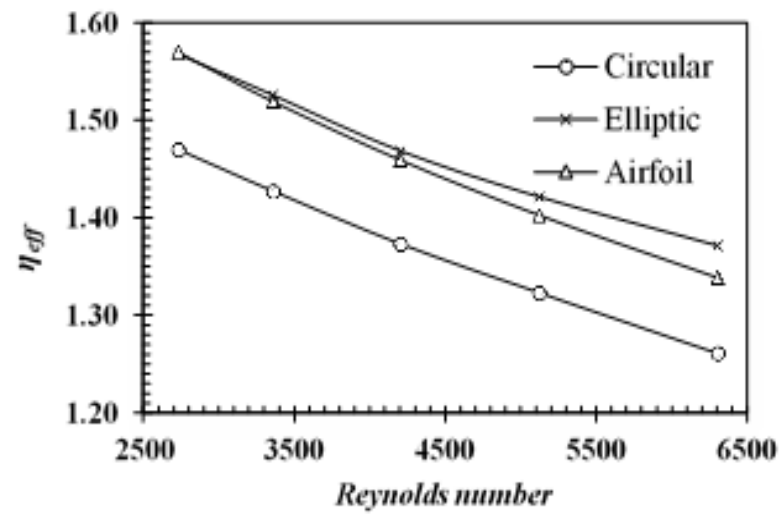

Figure 24. Effect of pin fin geometry on performance coefficient $(\mathrm{Re}=6300)$

\section{CONCLUSION}

In this study, hydraulic and thermal performance of a platepin fin heat sink have been investigated. The fluid flow velocity, the geometric shape, the pin dimensions as well as the location of pin fins have been studied as the influential parameters on the heat sink performance. The steps to this study and the results are as follows:

(1) The numerical method adopted in this study has been validated, being compared with previous experimental studies.

(2) The grid study has been carried out by examining three different grids and given the items such as improvement in the results, computation time and costs, the 879,000 cells grid have been applied to proceed the study.

(3) The results indicate that increasing the inlet velocity, and consequently the Reynolds number, reduces the thermal and overall performance of the heat sink, whether using a plate or any other type of pin fin.

(4) In order to investigate the effect of inserting pin fin into the heat sink, a pin with $\mathrm{E} / \mathrm{W}$ ratio of 0.3 , which has the least impact on the hydraulic and thermal performance of the heat sink, has been considered as the base of comparisons.

(5) By employing pin fins for the heat sink, thermal resistance declines by $33 \%$ on average and the overall performance rises by $24.5 \%$ on average.

(6) As the geometric ratio, $\mathrm{E} / \mathrm{W}$, is increased, the maximum temperature of the base and the thermal resistance of the heat sink decline and the Nusselt number rises. On the other hand, the hydraulic performance is notably affected and the pressure drop as well as the friction coefficient increase. The same behavior was observed for the three geometries studied.

(7) Based on the diagrams for the overall performance and considering manufacturing costs, 0.3 and 0.6 were chosen as the largest and the smallest geometric ratios, respectively, to be explored.

(8) As compared to the circular pin, the elliptic geometry provides more desirable thermal and overall performance coefficients, regardless of $\mathrm{E} / \mathrm{W}$ ratio.

(9) For circular and elliptic geometries, increasing E/W, causes the overall performance coefficient to decline; while, in the case of airfoil geometry, increasing E/W to a certain extent enhances the overall performance, exceeding which causes the overall performance to decline.

(10) Changing the location of the pin has a minor impact on improving the thermal performance. For the geometric ratio of 0.3 , the diagram of thermal resistance versus dimensionless distance has two minimum points, while there is one minimum point for the geometric ratio of 0.5 . In both cases, maximum thermal resistance variation is less than $1.5 \%$.

\section{REFERENCES}

[1] Kandlikar SG. (2014). Single-phase liquid flow in minichannels and microchannels. Heat Transfer and Fluid Flow in Minichannels and Microchannels (Second Edition). Butterworth-Heinemann, Oxford 103-174. http://dx.doi.org/10.1016/B978-0-08-098346-2.00003-X

[2] Qu W, Mudawar I. (2002). Experimental and numerical study of pressure drop and heat transfer in a single-phase micro-channel heat sink. International Journal of Heat and Mass Transfer 45: 2549-2565. http://dx.doi.org/10.1016/S0017-9310(01)00337-4

[3] Culham JR, Muzychka YS. (2001). Optimization of plate fin heat sinks using entropy generation minimization. IEEE Transactions on Components and Packaging Technologies 24: 159-165. http://dx.doi.org/10.1109/6144.926378

[4] Bar-Cohen A, Iyengar M. (2003). Least-energy optimization of air-cooled heat sinks for sustainable development. IEEE Transactions on Components and Packaging Technologies 26: 16-25. http://dx.doi.org/10.1109/TCAPT.2003.811463

[5] Khan WA, Culham J, Yovanovich M. (2006). The role of fin geometry in heat sink performance. Journal of Electronic Packaging 128: 324-330. http://dx.doi.org/10.1115/1.2351896

[6] John T, Mathew B, Hegab H. (2010). Parametric study on the combined thermal and hydraulic performance of single phase micro pin-fin heat sinks part I: Square and circle geometries. International Journal of Thermal Sciences 49: 2177-2190.

http://dx.doi.org/10.1016/j.ijthermalsci.2010.06.011

[7] Liu M, Liu D, Xu S, Chen Y. (2011). Experimental study on liquid flow and heat transfer in micro square pin fin heat sink. International Journal of Heat and Mass Transfer 54: 5602-5611. http://dx.doi.org/10.1016/j.ijheatmasstransfer.2011.07.0 13

[8] Yuan W, Zhao J, Tso CP, Wu T, Liu W, Ming T. (2012). Numerical simulation of the thermal hydraulic performance of a plate pin fin heat sink. Applied Thermal Engineering 48: 81-88. http://dx.doi.org/10.1016/j.applthermaleng.2012.04.029

[9] Yu X, Feng J, Feng Q, Wang Q. (2005). Development of a plate-pin fin heat sink and its performance comparisons with a plate fin heat sink. Applied Thermal Engineering 
25: $173-182$.

http://dx.doi.org/10.1016/j.applthermaleng.2004.06.016

[10] Knight W, Hall DJ, Goodling JS, Jaeger RC. (1992). Heat sink optimization with application to microchannels. IEEE Transactions on Components, Hybrids, and Manufacturing Technology 15: 832-842. http://dx.doi.org/10.1109/33.180049

[11] Goldberg N. (1984). Narrow channel forced air heat sink. IEEE Transactions on Components, Hybrids, and Manufacturing Technology 7: 154-159. http://dx.doi.org/10.1109/TCHMT.1984.1136326

[12] Tuckerman DB, Pease R. (1981). High-performance heat sinking for VLSI. IEEE Electron Device Letters 2: 126129. http://dx.doi.org/10.1109/EDL.1981.25367

[13] Koz M, Kosar A. (2010). Parameter optimization of a micro-heat sink with circular pin fins. ASME 8th Conference on Nanochannels, Microchannels and Minichannels, Montreal, Canada, pp. 1-5. http://dx.doi.org/10.1115/FEDSM-ICNMM2010-30473

[14] Sivakumar A, Alagumurthi N, Senthilvelan T. (2015). Experimental and numerical investigation of forced convective heat transfer coefficient in nanofluids of $\mathrm{Al} 2 \mathrm{O} 3 /$ water and $\mathrm{CuO} / \mathrm{EG}$ in a serpentine shaped microchannel heat sink. International Journal of Heat and Technology 33: 155-160. http://dx.doi.org/10.18280/ijht.330121

[15] Hegde PG, Seetharamu K. (2008). Effects of nonuniform base heating in multi stack microchannel heat sinks used for cooling high heat flux electronic chips and devices. Electronic Manufacturing Technology Symposium (IEMT), 33rd IEEE/CPMT International, IEEE, pp. 1-6. http://dx.doi.org/10.1109/IEMT.2008.5507856

[16] Wang X, Zhang W, Liu H, Chen L, Li Z. (2009). Numerical simulation on variable width multi-channels heat sinks with non-uniform heat source. Electronic Packaging Technology \& High Density Packaging, ICEPT-HDP'09. International Conference on, IEEE, pp. $1155-1158$. http://dx.doi.org/10.1109/ICEPT.2009.5270609

[17] Huang CH, Chen YH. (2014). An optimal design problem in determining non-uniform fin heights and widths for an impingement heat sink module. Applied Thermal Engineering 63: 481-494.

http://dx.doi.org/10.1016/j.applthermaleng.2013.11.008

[18] Adewumi O, Bello-Ochede T, Meyer JP. (2015). Constructal design of single microchannel heat sink with varying axial length and temperature-dependent fluid properties. International Journal of Heat and Technology 34: $167-172$ http://dx.doi.org/10.18280/ijht.34Sp0122

[19] Liang C, Zeng S, Li Z, Yang D, Sherif S. (2016). Optimal design of plate-fin heat sink under natural convection using a particle swarm optimization algorithm. International Journal of Heat and Technology 34(2): 275 280

http://dx.doi.org/10.18280/ijht.340217

[20] Saravanan V, Umesh CK, Hithaish D, Seetharamu K. (2018). Numerical investigation of pressure drop and heat transfer in pin fin heat sink and micro channel pin fin heat sink. International Journal of Heat and Technology 36: 267-276.

http://dx.doi.org/10.18280/ijht.360136
[21] Wilcox DC. (2006). Turbulence Modeling for CFD. DCW Industries.

[22] Rafiee SE, Sadeghiazad M, Mostafavinia N. (2015). Experimental and numerical investigation on effect of convergent angle and cold orifice diameter on thermal performance of convergent vortex tube. Journal of Thermal Science and Engineering Applications 7: 041006. http://dx.doi.org/10.1115/1.4030639

[23] Rafiee SE, Sadeghiazad MBM. (2016). Threedimensional computational prediction of vortex separation phenomenon inside the Ranque-Hilsch vortex tube. Aviation 20: 21-31. http://dx.doi.org/10.3846/16487788.2016.1139814

[24] Rafiee S, Sadeghiazad M. (2017). Experimental and 3D CFD investigation on heat transfer and energy separation inside a counter flow vortex tube using different shapes of hot control valves. Applied Thermal Engineering 110: 648-664.

http://dx.doi.org/10.1016/j.applthermaleng.2016.08.166

[25] Sriromreun P, Sriromreun P. (2018). Experimental and numerical studies of heat transfer characteristics for impinging jet on dimple surfaces. Chemical Engineering Transactions 70 : https://doi.org/10.3303/CET1870213

[26] Misirlis D, Vlahostergios Z, Salpingidou C, Yakinthos K. (2018). Investigation of heat transfer and flow field development around a low-pressure turbine blade with the use of open source CFD tools. Chemical Engineering Transactions 70: 757-62. https://doi.org/10.3303/CET1870127

[27] Zhou F, Catton I. (2011). Numerical evaluation of flow and heat transfer in plate-pin fin heat sinks with various pin cross-sections. Numerical Heat Transfer, Part A: Applications $\quad 60$ : 107-128. http://dx.doi.org/10.1080/10407782.2011.588574

[28] Jonsson H, Moshfegh B. (2001). Modeling of the thermal and hydraulic performance of plate fin, strip fin, and pin fin heat sinks-influence of flow bypass. IEEE Transactions on Components and Packaging Technologies 24: 142-149. http://dx.doi.org/10.1109/6144.926376

\section{NOMENCLATURE}

$\begin{array}{ll}A_{C} & \text { cooled surface } \\ D & \text { pin fin diameter } \\ E & \begin{array}{l}\text { the lateral dimension of pin normal to flow } \\ \text { direction } \\ \text { friction coefficient } \\ \text { channel height }\end{array} \\ H & \text { heat sink base thickness } \\ H_{b} & \text { plate fin and fin height } \\ H_{f} & \text { the dimensionless distance between the } \\ L^{*} & \text { center of pin fin and the centre of heat flux } \\ & \text { region } \\ & \text { heat sink length in direction of flow } \\ L & \text { heat flux region length } \\ L_{h} & \text { the distance between the center of pin fin and } \\ L_{p} & \text { the channel inlet } \\ M & \text { dynamic viscosity coefficient } \\ N & \text { Number of pin fins } \\ N u & \text { Nusselt number }\end{array}$


$k_{s}$

$P$

$Q$

$t$

$T$

$T_{S a v g}$

$T \propto$

$\bar{u}$

W thermal conduction coefficient for the solid

part

pressure

dissipated heat

Time

temperature

average temperature of the surface

inlet fluid temperature

mean velocity

channel width

\section{Greek symbols}

$\eta_{\text {eff }} \quad$ overall performance coefficient of heat sink

$\rho \quad$ fluid density

$\mu \quad$ dynamic viscosity of laminar flow

$\mu_{t} \quad$ dynamic viscosity of turbulent flow

$\sigma_{l} \quad$ empirical constant of laminar flow

$\sigma_{t} \quad$ empirical constant of turbulent flow

\section{Subscripts}

$\begin{array}{ll}l & \text { laminar } \\ t & \text { turbulent }\end{array}$

